\title{
Emerging Technologies: Public Health Educators' Knowledge And Attitudes Toward Global Sensor Networks
}

Taiwo Ajani, Ferrum College, USA

Elizabeth Stork, Robert Morris University, USA

\begin{abstract}
The world-wide networking of sensing devices planned by some computer corporations will have major implications for socio-political systems including national security, public health, and environmental monitoring. The early acceptance or failure of these deployments will depend on first users' knowledge and attitudes about it. Public health educators are on the forefront of environmental and global health research and policy and, as such, their involvement in development and implementation are critical to the public's acceptance of this technology. This correlation study used two adapted instruments - one on knowledge of technology and one on attitudes - and captured demographic information on 155 public health faculty. The authors found that Public Health university educators were not very knowledgeable about sensor systems in general (76\% with little to no knowledge); their highest level of knowledge was on benefits and uses of global sensor networks (22\% had some or more knowledge), and lowest was on plans to deploy them. The sample had moderately positive attitudes (range 1-7) about the idea of global sensor deployment $(M=4.57, N=155)$ and a slight positive correlation between knowledge and attitudes on global sensor networks.
\end{abstract}

Keywords: Global Sensor Network; Public Health; Technology Acceptance; Knowledge; Attitudes

\section{INTRODUCTION}

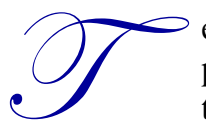

echnology enhances human capacity to understand and dominate the environment. Integrated principles borrowed from diverse fields are yielding new and unprecedented gains that are making this possible, thereby improving prospects for securing lives, properties, the environment, and health. Recent terrorist attacks and man-made and natural disasters in several corners of the globe underscore a need for early threat detection technologies. These can assist decision-makers in honing in on the most probable causes or sources and facilitate response measures. Emerging technologies, such as sensing devices for planet-wide networking, have promise for early detection of a diversity of threats; however, real capabilities are undeliverable unless the innovation is understood and valued. The threat of rejection of innovations can be mitigated if the attitudes of potential users and decision-makers are known. Attitudes are important in predicting the reaction of people to new ideas and things (Fishbein, 1975). Once known, perceptions can be influenced with exposure to and information about the products and their uses.

The planned implementation of global sensor networks that are under development at some companies Hewlett Packard, for instance - and their intended and potential uses make this study an important one for practitioners in both the field of information systems and in public health because of their dependence on reliable data for decision-making during emergency situations.

\section{Emerging Technologies}

Although sensing or sensor devices have been in existence for decades, contemporary utilization for planetwide network systems is novel, making them emerging innovations about which possibility, value, and 
consequences are still a mystery. The process of information technology acceptance often commences before individuals have interacted with the technology. The success or failure of a new technology depends on users' acceptance, which depends on the preconceived knowledge, perceived usefulness, and the users' behavioral intention toward it (Davis, Bagozzi, \& Warshaw, 1989; Davis \& Venkatesh, 2004; Jain, 2006). One significant component of technology diffusion is the knowledge about the availability of a new technology and its potential (Rogers, 1995). Rogers observed that people's perception of new innovations are often not based on scientific assessments, but rather subjective evaluations of what is learnt through social channels or what is perceived as advantageous to the user. By implication, awareness becomes a significant component of knowledge about an innovation.

Knowledge is the first stage of the innovation-decision period for potential users or adopters; prospective users must first learn about the innovation and then they must be persuaded about the value of it. A theoretical framework developed by Attewell (1992) to study the diffusion of complex technologies in organizations revealed that knowledge, including technical skills, was an important barrier to diffusion. He found that organizations tend to delay the adoption of complex technologies until employees acquire sufficient technical know-how to implement and operate new innovations successfully. Technology acceptance models have been tested on post-prototype technology (Davis \& Venkatesh, 2004). One reason for the development of a myriad of models is the importance of technology to development. According to Jain (2006), research findings are relevant when developing costly or risky technologies because an early estimation of technology acceptance can be made before too many limited resources are expended, allowing for modification of the technology before implementation. For an emerging innovation like the sensor network system, awareness of potential users' pre-implementation knowledge and attitudes is important because of potential ramifications that may not yet be obvious to developers.

\section{Sensors and Sensor Networks}

Advances in micro-electro-mechanical systems (MEMS) technology, coupled with wireless communications and digital electronics, have enabled the development of low power, low cost sensor nodes that are not only portable in size but multifunctional and have capabilities to communicate, untethered, over short distances (Akyildiz, Sankarasubramaniam, \& Cayirci, 2002). Sensor networks represent a huge improvement over traditional sensors. A sensor network is composed of a large number of sensor nodes, which can be densely deployed in remote regions, inaccessible terrains, and disaster zones (Akyildiz et al., 2002). Their protocols and algorithms are designed to have self-organizing capabilities. Akyildiz and his team pointed out that the unique feature of sensor networks is the cooperative nature of sensor nodes: "sensor nodes are fitted with an on-board processor...instead of sending the raw data to the nodes responsible for the fusion, sensor nodes use their processing abilities to locally carry out simple computations and transmit only the required and partially processed data" (p. 394) which enable them to be used in a diverse range of applications.

Technology companies have conceived a wide range of practical applications for sensor networks, using them for warning, early detection, and prevention in engineering, wildlife settings, "smart" buildings, and disaster response systems (Liaskovitis, 2009). Kornguth (2005) suggested the use of advanced sensor systems as integral components of bio-detection technologies designed for warning, detection, and surveillance of bio-terror and agents of biological warfare. To be fully prepared for biological threat prevention and management, Kornguth (2005) suggested multiplexed, multi-array sensor systems should be a component of a network for rapid detection and identification. This sensor system ideally would be capable of recognizing all bacterial or viral genomic materials that determine bio-agents' virulent natures, pathogenicities, and antigenic characteristics.

Until now, one of the most difficult aspects of creating a detection system was the development of multiplexed sensors capable of detecting several toxic agents. This is no longer the case. As a result of recent advances in science and engineering, the once science-fiction idea of a globally deployed wireless network of sensors - or sensors as components of larger systems - is under development for national security. An example is the Hewlett Packard Central Nervous System for the Earth (CeNSE) which is comprised of sensors able to be deployed on a global scale for on-site monitoring of physical locations. This has involved the development of nanotechnology-based sensing devices, embedded in everyday electronics, and capable of detecting structural and environmental threats. Hartwell, senior researcher and project team leader of the Hewlett Packard Central Earth 
Nervous System program, envisions sensing nodes about the size of a pushpin affixed to standing structures such as bridges and buildings to warn of structural pressures; they might also be embedded along public roadsides to monitor traffic patterns, road conditions, and weather changes (Wylie, 2009). These networks of sensors will have the capability for recognizing patterns that enable quick identification of aberrant situations. Some systems will contain analytical components that will accelerate investigations by health responders (Berndt, Fisher, Craighead, Hevner, Luther, \& Studnicki, 2007). These can be coupled seamlessly with an integrated communication capability able to convert large scale data into immediately useable information (Kornguth, 2005) for such things as biological agent detection for use by responders in the field (Stark, 2007).

\section{Role of Public Health}

The field or sector that requires all of these functionalities in one or more of such systems is public health. Public health is interested in human health as it is influenced by - and it influences - the environments in which humans reside. Any perturbation or changes to the environment, either by natural or artificial infusion of a chemical, a technology or other entity, becomes a concern for the public health field. Although the benefits of sensing devices are marketed by corporations, hence the promotion of the data these sensors can deliver, the risks are yet to be determined. Public health professionals' perceptions of risks and benefits are factors that are critical for the acceptance of a widespread use of sensing devices.

It is not known what public health professionals know about sensor networks or what their perceptions and attitudes are about them. The main purpose of this study was to learn about the relationship between public health professors' knowledge about sensors and attitudes toward planet-wide sensor systems' deployment. Public health was chosen because it has significant responsibility for educating those who might be tasked as first responders, participating and advising research teams, policy makers, and national agencies, across the United States. A second purpose of the study was to create a model to predict attitudes about the deployment of sensor systems based on knowledge and demographic factors of public health university faculty and researchers. An understanding of public health professionals' knowledge about this emerging technology, and their attitudes about it, will enable system designers to predict behavioral patterns toward use of this technology which can lead to effective implementation and integration strategies.

\section{METHODS}

The aim of this study was to determine whether knowledge of public health professionals about world-wide sensor systems would correlate with attitudes and whether any relationship between the two variables could enable the creation of a predictive model for those seeking to construct and deploy a network that these professionals would value and use.

Participants were drawn from the Association of Schools of Public Health in the U.S. A simple random sampling technique - a blind drawing of ten schools from all 48 school names - was used to select the sample of schools. The sampling frame consisted of faculty whose contact information was found on the ten university websites. A request to complete the web-based survey, along with a description of the study, was emailed to 1,553 public health faculty university email addresses in December 2010. The number of potential participants who actually received the request and survey could not be determined, but of the 205 returned, 155 were complete.

The study participants were 55\% male and $45 \%$ female. Their ages ranged the full spectrum of decade intervals on the survey - under 40 (17\%) to over 70 (5\%), most (78\%) ages from 40 through 69 [40-49 (23\%), 50-59 (29\%), 60-69 (26\%)]. Education levels, as expected, were high - 75\% with doctorate degrees and 19\% with MD degrees. Socio-politically, the majority were liberal (73\%), $17 \%$ were centrist, and $10 \%$ were conservative.

More than $40 \%$ of the respondents had been working in public health education and research for more than 25 years; about $10 \%$ spent less than five years, $15 \%$ have been in the field $6-10$ years, $13 \%$ spent $11-15$ years, and $10 \%$ have been in the field 16-20 years. Core areas of fields of interest were widely distributed with Epidemiology the most represented (23\%). Health Policy Management (14\%), Biostatistics (13\%), Social and Behavioral Sciences (10\%), and Environmental Health Sciences (10\%), and Global Health \& Nutrition and Maternal \& Child Health were each represented by $5.5 \%$ of the respondents. The remaining $14 \%$ did not specify or selected "Other." 
The survey employed two instruments, including a Knowledge scale that was adapted and expanded for this study from Imran (2009) and the Semantics Differential Scale (SDS) (Christensen \& Knezek, 1998; Osgood, Suci, \& Tannenbaum, 1957). Both scales were combined with demographic questions added to form one 22-item questionnaire that took about 10 minutes to complete. The first section included demographic questions asking gender, age, education, sub-specialty, work experience, use of primary and secondary data in research, and sociopolitical learning. The second section contained seven questions on knowledge constructs about the following sensors/biosensors - use of senor/biosensors, capability of sensor/biosensor systems, impact of senor/biosensor systems, cost of deploying, benefits of deploying, type of business or organizational activities in which sensors/biosensors can be deployed, and any plans to deploy a worldwide sensor network system. Response categories ranged from 1 to $5,1=$ none and $5=$ expert knowledge. Reliability was measured using Cronbach's alpha and was found to be 0.91 .

The Semantics Differential Scale (SDS) (Christensen \& Knezek, 1998; Osgood, Suci, \& Tannenbaum, 1957) used to measure the attitudes of the participants to the global deployment of sensor systems followed. The SDS is a seven-point bipolar rating scale, with seven rating points to choose from, that uses adjective pairs to rate attitudes on ten items: Unsafe (1)....Safe (7), Meaningless...Meaningful; Uninspiring...Motivating; Tedious...Interesting; Outdated...Innovative; Bad...Good; Complicated...Simple; Useless...Useful; Unreliable...Reliable; Time consuming...Time saving. A high rating of 7 is equal to a very positive attitude where a low rating of 1 is equal to a very negative attitude. A factor analysis was performed to test this adapted scale; Complicated...Simple loaded by itself as a second component. Without that pair of adjectives, the Cronbach alpha was 8.69. The Cronbach alpha for all items was a respectable 0.83 ; therefore, the item was kept in the scale.

Of the 205 surveys returned, 155 were fully completed. Scores for each of the items on the Attitude scale (SDS) and the Knowledge scale were summed and a mean score on each for every participant, as well as a total score for each demographic category, was calculated. Items and total scores on the Knowledge scale were correlated with items and total scores on Attitudes using a two-tailed test.

\section{RESULTS}

In this study, public health educators $(\mathrm{N}=155)$ had very little knowledge about sensors. Forty percent had no knowledge and another $36 \%$ said they had little knowledge. Only $8 \%$ claimed a lot or expert knowledge.

Seventy-eight percent of respondents had "none" to "little knowledge" about the use (M = 1.79) of sensor systems or their benefits $(\mathrm{M}=1.73)$. More than $81 \%$ of respondents had "none" to "little knowledge" about capability $(M=1.69)$ or impact $(M=1.67)$ of them. Some public health educators had knowledge about the types of organizations $(M=1.67)$ in which sensors could be deployed $(83 \%)$, but most $(94 \%)$ had "none" to "little knowledge" about any plans $(\mathrm{M}=1.35)$ for deploying such systems, and only $10 \%$ had some knowledge about the costs $(\mathrm{M}=1.48)$ of deploying them.

In order of mean scores on a scale of 1 (no knowledge) to 5 (expert knowledge), the least amount of knowledge was on plans to deploy a global sensor network. Their highest level of knowledge was about benefits and uses of global sensor networks. The range of scores was 1.0 to 5 (see Table 1).

Table1: Participants' Mean Knowledge Scores (Scale of 1-5)

\begin{tabular}{|l|c|c|}
\hline \multicolumn{1}{|c|}{ Knowledge } & \% None To Little & Mean \\
\hline Total Knowledge & 76 & 1.63 \\
\hline Use of sensors/biosensors & 78 & 1.79 \\
\hline Capability of sensor/biosensor systems & 82 & 1.69 \\
\hline Impact of sensor/biosensor systems & 80 & 1.67 \\
\hline Cost of deploying sensor/biosensor systems & 90 & 1.48 \\
\hline Benefits of deploying sensor/biosensor systems & 78 & 1.73 \\
\hline Type of business or organizational activities in which sensors/biosensors can be deployed & 83 & 1.67 \\
\hline Any plans to deploy a worldwide sensor network systems & 94 & 1.35 \\
\hline
\end{tabular}


Attitudes toward sensor deployment were moderately favorable $(\mathrm{M}=4.57, \mathrm{~N}=155)$. The range was 1.9 to 6.5. Mean scores on individual items were above the median of 3.5, indicating favorable attitudes. Simplicity arguably a favorable attitude - had the lowest mean $(\mathrm{M}=2.48)$. Public health educators consider the technology complicated. They also judged reliability only slightly higher than neutral $(\mathrm{M}=3.97)$. As a time-saving device, they scored higher than seeing them as time-consuming devices $(M=4.35)$. Motivating outscored uninspiring $(M=$ 4.55), safe outscored unsafe $(M=4.76)$, and good outweighed bad $(M=4.97)$. Attitude scores were highest on useful $(M=5.12)$, interesting compared with tedious $(M=5.34)$, and the highest on innovative $(M=5.38)$ versus outdated (see Table 2).

Table 2: Participants' Mean Attitude Scores (Scale of 1-7)

\begin{tabular}{|l|c|c|}
\hline \multicolumn{1}{|c|}{ Attitudes } & \% At Least Moderately Favorable & Mean \\
\hline Unsafe...Safe & 52 & 4.76 \\
\hline Meaningless...Meaningful & 63 & 4.83 \\
\hline Uninspiring...Motivating & 48 & 4.55 \\
\hline Tedious...Interesting & 69 & 5.34 \\
\hline Outdated...Innovative & 75 & 5.38 \\
\hline Bad...Good & 55 & 4.97 \\
\hline Useless...Useful & 63 & 5.12 \\
\hline Unreliable...Reliable & 24 & 3.97 \\
\hline Time consuming...Time saving & 38 & 4.35 \\
\hline Complicated...Simple & 2 & 2.48 \\
\hline
\end{tabular}

\section{Demographic Variations on Knowledge and Attitudes}

Oldest public health educators (70+) had the highest levels of knowledge about sensors $(M=1.98)$ and the most favorable attitudes $(\mathrm{M}=4.87)$. Those under 50 had a mean knowledge score of 1.26 and attitude scores of 4.31. These differences, by age, were not statistically significant. Number of years' working experience did not have any significance on levels of knowledge or on attitudes. Means were different across all categories, only by .21 on knowledge and .46 on attitudes.

Level of education differences also were not statistically significant, although means were highest on knowledge for medical doctors $(M=1.72)$. Very few master's and bachelor's level respondents rendered those comparisons irrelevant. Attitudes did not differ by education level (range $\mathrm{M}=4.40-4.58$ ).

Socio-political perspective did not influence knowledge or attitudes significantly; means varied only by .29 on knowledge and .48 on attitudes. However, mean scores were higher for those who identified as $1(\mathrm{M}=4.9)$ and 2 $(\mathrm{M}=4.8)$ on a 7-point scale of very conservative (1) to very liberal (7) $(\mathrm{M}=4.48)$.

Differences in knowledge, by gender, were found to be statistically significant $[F(1,155)=13.49, p=0.00]$ but not in attitudes. By public health discipline, differences in knowledge were also significant $[\mathrm{F}(8,155)=3.281, \mathrm{p}$ $=0.002]$. As would be expected, those in environmental health sciences were most knowledgeable $(M=2.31)$. They also, by mean, had the most favorable attitudes. However, attitude differences between disciplines were not found to be significant.

\section{Correlation between Knowledge and Attitudes}

Total Knowledge had a small positive correlation with total Attitude mean score $(\mathrm{r}=0.286, \mathrm{~N}=155, \mathrm{p}=$ .000 ), sharing nearly $8 \%$ of their variance. Individual Knowledge items had a small positive correlation with the total Attitude mean score about global sensor networks - with the exception of benefits of deploying, which was moderate $(\mathrm{r}=0.319, \mathrm{~N}=155, \mathrm{p}=.000)$ - with moderate levels of knowledge explaining $10 \%$ of the favorable attitudes (see Table 3). 
Table 3: Individual Knowledge Items Correlations with Total Attitudes

\begin{tabular}{|l|c|c|}
\hline \multicolumn{1}{|c|}{ Knowledge } & Pearson r & Sig.(2-Tailed) \\
\hline Use of sensor/biosensor & 0.248 & 0.002 \\
\hline Capability of sensor/biosensor systems & 0.269 & 0.001 \\
\hline Impact of sensor/biosensor systems & 0.262 & 0.001 \\
\hline Cost of deploying sensor/biosensor network systems & 0.256 & 0.001 \\
\hline Benefits of deploying sensor/biosensor network systems & 0.319 & 0.000 \\
\hline Type of business or organizational activities in which sensors/biosensors can be deployed & 0.287 & 0.000 \\
\hline Any plans to deploy a worldwide sensor network system & 0.133 & 0.098 \\
\hline
\end{tabular}

\section{DISCUSSION}

Public health educators are from diverse discipline areas that cut across a wide swath of human needs and services, including environmental health, biostatistics, epidemiology, nutrition, health policy, and global health. Despite their low level of knowledge about world-wide sensor systems and networks, it is remarkable that respondents were generally favorable about them. Meaningful, innovative, interesting, and useful were adjectives agreed to by more than $60 \%$ of the respondents and safe and good by more than half. However, almost three quarters of respondents thought global sensor systems were complicated things. Also, most indicated they were skeptical about their reliability or time-saving attributes. Being male and being a practitioner of environmental health were factors slightly more likely to influence more knowledge about sensor systems. None of the variables examined were found to play a role in attitudes. No demographic factors had significant relationships between knowledge and attitudes about these systems.

The findings of this research suggest that attitudes toward a global deployment of sensor systems and network are somewhat dependent on individuals' knowledge about them. Benefits of sensor systems - a component of the knowledge scale - was observed to have the strongest correlation with attitudes, which suggests that this component could be a strong driver that could be employed to influence more positive attitudes toward global sensor network deployment. According to Rogers (1995), a major and significant component of the Innovation Diffusion Theory is knowledge about the availability and potentials of a new technology. He observed that people's perceptions about new innovations are not often based on scientific assessments, but rather on a subjective evaluation of what is learnt through social channels or what is perceived as advantageous. It is not known how much of the knowledge they ( $\mathrm{PH}$ respondents) do have was learnt through social channels or professional ones. Considering the low level of knowledge about sensors and plans for a worldwide sensor network deployment, the respondents' attitudes about this technology may stem from what they perceive as advantages from a public health standpoint (useful, good, time-saving, reliable, safe) or from an academic standpoint (innovative, meaningful, interesting, motivating, complicated). These may, at this time, given the dearth of knowledge, be preconceptions about global sensor systems and networks.

\section{CONCLUSION}

Knowledge, attitudes, and behavioral intentions of potential users have an impact on the ultimate acceptance or failure of emerging technologies, the costs of which are often enormous. To avoid failure, minimize complications, and improve the prospect of acceptance of promising innovations, knowledge, and attitudes that may impact their acceptance and usage should be investigated during the various stages of prototype development. There are always concerns about the failure of technologies due to user's preconceptions (Davis \& Venkatesh, 2004; Jain, 2006). Predictive and stable measures of perceived usefulness can be captured from users who have received information about the functionality of a system, even if they have not had direct hands-on experience with it. Through the mock-up description of the concept of global sensor deployment that was provided for this study - an approach also used by Davis and Venkatesh (2004) - respondents generally showed that they perceived the technology as useful. Perceived usefulness is a determinant of behavioral intention toward a technology.

Rogers (2005) stated that prospective users must first learn about an innovation and this is subsequently followed by persuasion about the values of such innovation. The finding of moderately favorable attitudes of this small sample of public health educators, even without them having specific knowledge, is encouraging for the 
proponents of a global sensor network. Whether public health professionals become users or not, they will have instrumental roles to play in research and testing, education, policy recommendations, and usage. They should be involved or informed about development and plans by inventors and companies' intent on implementing them, and with increased levels of knowledge and involvement, they have a more than reasonable chance of becoming persuaded about the value of global sensor network systems.

\section{AUTHOR INFORMATION}

Taiwo Ajani is an Assistant Professor of Computer Information Systems at Ferrum College School of Social Sciences and Professional Development. He has a cross-disciplinary background in Information Systems and the Life Sciences. He earned his Doctor of Science in Information Systems and Communication from Robert Morris University, and a Master of Science in Medical Sciences from the University of South Florida. Dr. Ajani currently teaches classes in information systems, networking, computer literacy, freshman and senior research seminar. E-mail: tajani@ferrum.edu (Corresponding author)

Elizabeth Stork is an Associate Professor of Organizational Leadership at Robert Morris University's School of Communications and Information Systems. She earned her Ph.D. in Non-Profit Administration from the School of Social Work, an M.A. in Sociology (Gender, Race, \& Class), and an MSW in Non-Profit Administration from the University of Pittsburgh. Stork currently teaches graduate courses in organizational leadership, decision making, and research methods. E-mail: $\underline{\text { stork@rmu.edu }}$

\section{REFERENCES}

1. Akyildiz, I. F., Su, W., Sankarasubramaniam, Y., \& Cayirci, E. (2002). Wireless sensor networks: A survey. Computer Network, 38, 393-422.

2. Attewell, P., (1992). Technology diffusion and organizational learning: The case of business computing. Organization Science, 3(1) 1-19.

3. Berndt, D. J., Fisher, J. W., Craighead, J. G., Hevner, A. R., Luther, S., \& Studnicki, J. (2007). The role of data warehousing in bioterrorism surveillance. Decision Support Systems, 43(4), 1383-1403.

4. Christensen, R., \& Knezek, G. (1998). Parallel forms for measuring teachers' attitudes toward computers. Society of Information Technology \& Teacher Education (SITE)'s 9th International Conference, Washington, DC, March 13, 1998.

5. Davis, F. D., Bagozzi, R. P., \& Warshaw, P. R. (1989). User acceptance of computer technology: A comparison of two theoretical models. Management Science, 25(8), 982-1003.

6. Davis, F. D., \& Venkatesh, V. (2004). Toward pre-prototype user acceptance testing of new information systems for software project management. Engineering Management, IEEE Transactions, 51(1), 31-46.

7. Fishbein, M. A. (1975). Belief, attitude, intention, and behavior: An introduction to theory research. London: Addison-Wesley.

8. Imran, A. (2009). Knowledge and attitude, the two major barriers to ICT adoption in LDC are the opposite side of a coin: An empirical evidence from Bangladesh. 42nd Hawaii International Conference on Systems Science (HICSS-42 2009), 1-10.

9. Jain, A. (2006). When preconceptions matters: Understanding pre-prototype usefulness of information technology, the case of a municipal wireless network. (Ph.D. Dissertation). Temple University, Philadelphia, PA. AAT 3247270.

10. Kornguth, S. (2005). Strategic actionable net-centric biological defense system. In D. Morrison et al. (Eds.), Defense Against bioterror: Detection technologies, implementation strategies and commercial opportunities (pp. 17-27). Dordrecht: Springer.

11. Liaskovitis, P. (2009). Deployment and organization strategies for sampling-interpolation sensor networks. (Ph.D. dissertation). University of California, San Diego, CA. Retrieved September 3, 2009 from Dissertations \& Theses: A\&I. AAT 3359864.

12. Osgood, C. E., Suci, G. J., \& Tannenbaum, P. H. (1957). The measurement of meaning. Urbana: University of Illinois Press.

13. Rogers, E. M. (1995). Diffusion of innovations (4 ${ }^{\text {th }}$ Ed.). New York: Free Press. 
14. Stark, A. M. (2007). LLNL researchers review biodetection technologies. News Release: NR-07-02-04. Retrieved 01/15/2010 from https://www.llnl.gov/news/newsreleases/2007/NR-07-02-04.html

15. Wylie, M. (2009). Earth calling: Turn off the lights! In Shell to use CeNSE for clearer picture of oil and gas reservoirs. Retrieved 08/09/2011 from http://www.hp.com/hpinfo/newsroom/press/2009/091105xa.ht 